\title{
A FUNCTIONAL SPLINT FOR THE C5 TETRAPLEGIC ARM
}

By D. Abrahams, R. D. Shrosbree, M.B., Ch.B. and A. G. Key, M.B., Ch.B. Spinal Cord Injury Centre, Conradie Hospital, Pinelands, Cape, South Africa

Abstract. An orthosis for a $\mathrm{C}_{5}$ complete tetraplegic providing active extension and pronation of the forearm is presented. It overcomes and prevents the occurrence of the flexed and supinated $\mathrm{C}_{5}$ tetraplegic arms. Technical data and a case report is included.

Key words: Tetraplegia; Spinal cord injury; Orthosis.

\section{Introduction}

THE all too frequent occurrence of the supinated, flexed tetraplegic arm with extended wrists (Fig. I) precludes the fitting of a motorised hand orthosis. The need arose to develop a functional splint which would provide pronation and elbow extension in order that the arm be in a functional position for the motorised orthosis to be practical.

After considerable thought and experimentation it was decided to make a light, spring-loaded lively splint making use of a similar 'twisting' principle that normally takes place during pronation of the forearm. This was to be incorporated onto a splint already devised by the Bio-Mechanical Department attached to the Spinal Cord Injury Unit of Conradie Hospital, which supplied elbow extension to the flail or paralysed arm.

\section{Description of the Splint}

A set of medium-sized geared hinge joints are used for the two side pieces, with the joint centres positioned opposite and in line with the medial and lateral

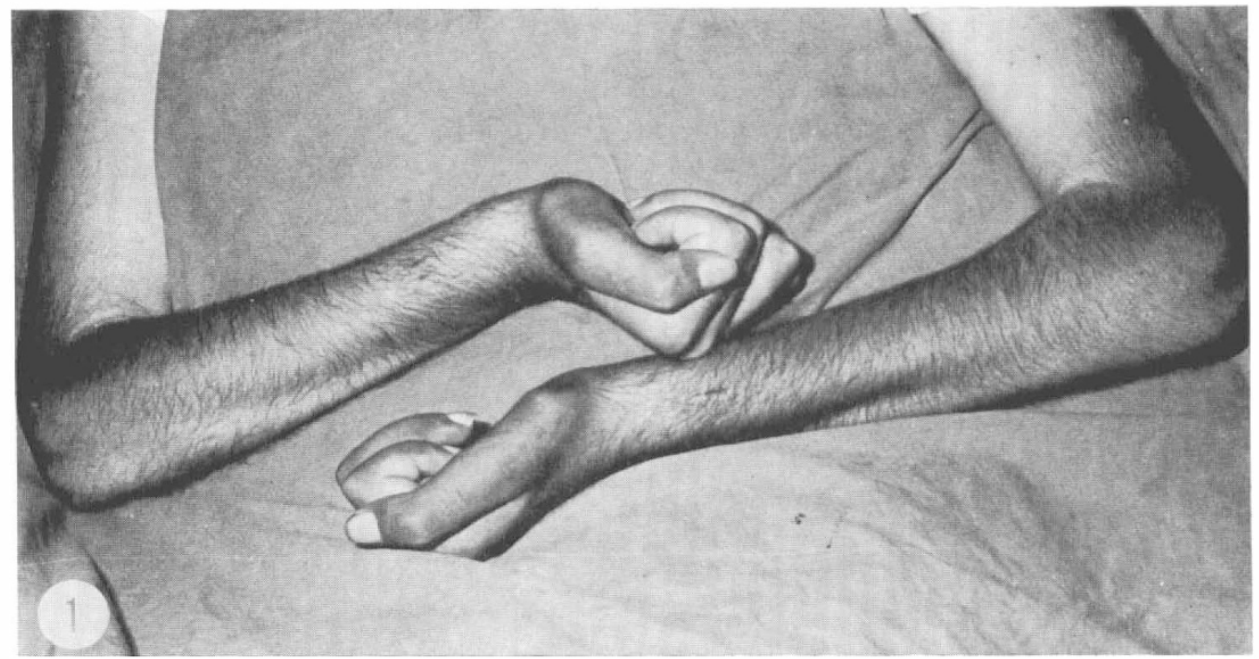

FIG. I

Typical position of $\mathrm{C}_{5}$ tetraplegic arm.

I98 
epicondyles respectively (Figs 2 and 5). Attached to the upper two arms of the joints, which extend proximally in line with the humerus, are two Duraluminium I-inch $(25 \mathrm{~mm})$ wide cuffs which are cut and shaped to the patient's size (Fig. 2). Approximately 3 inches $-3 \frac{1}{2}$ inches $(75 \mathrm{~mm}-87.5 \mathrm{~mm})$ distal to the joint centres a third cuff is attached to the lower joint arms. In setting the joint arms $\pm \frac{1}{4}$ inch $(6 \mathrm{~mm})$ clearance is allowed for on either side of the elbow joint to provide sufficient clearance to the epicondyle areas bilaterally. Care must be taken in setting the joints in order to provide a free moving joint. One of the reasons in selecting a geared joint is that the plate which forms the outside half of the joint is easily detachable and makes for relatively easy attachment of the coiled spring adaptor,
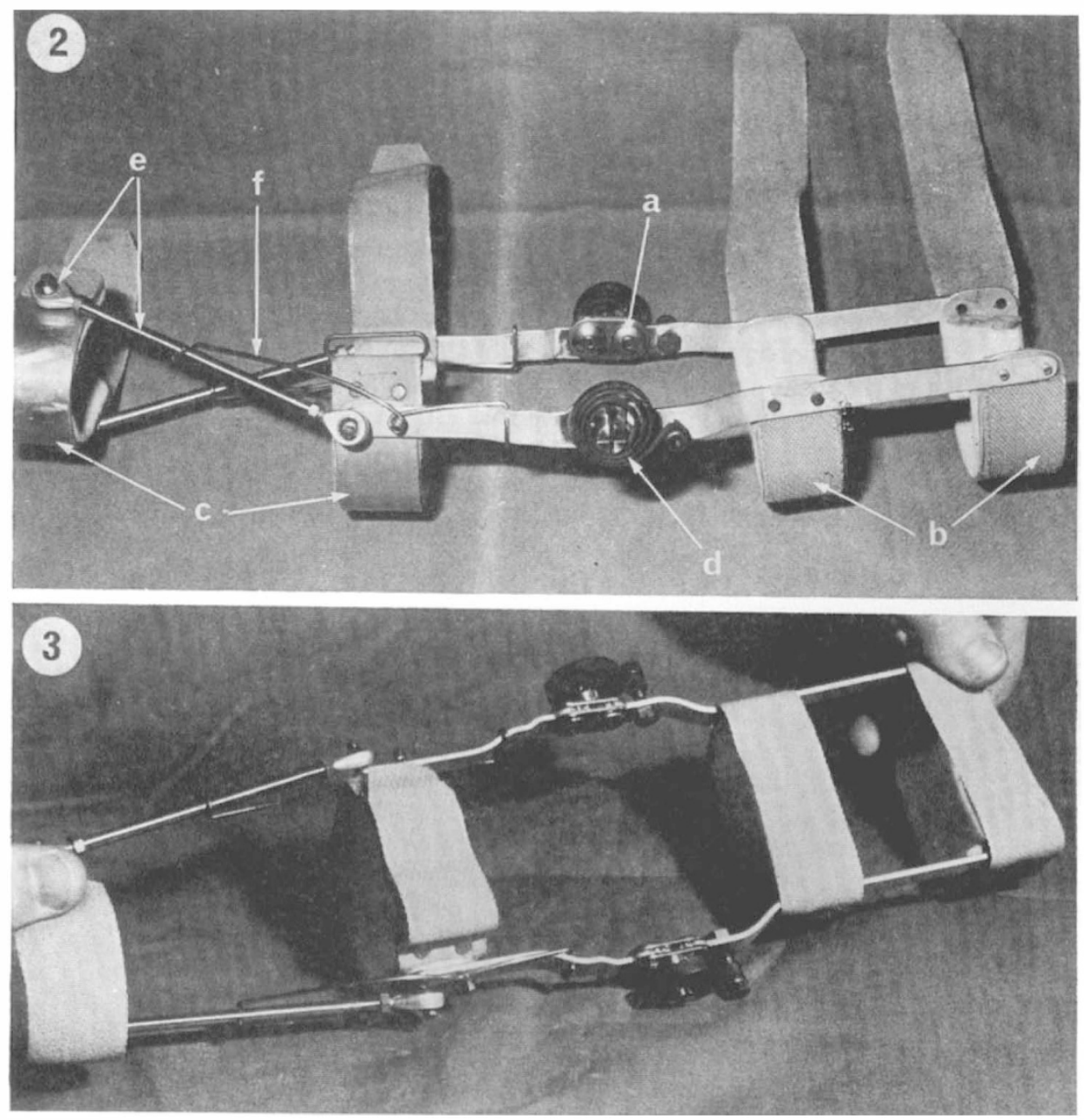

FIG. 2

Orthosis for left arm: (a) geared hinge joints, (b) cuffs for humerus, (c) upper forearm and wrist cuffs, (d) coiled spring and adaptor with four slits, (e) connecting rod with ball joints at ends and ( $f$ ) pronator spring.

FIG. 3

Orthosis supinated and extended. 
which together with the spring supplies the triceps action (Figs 3 and 4 ). The adaptor, by means of the four slits in its wall allows for quick adjustment of the spring tension (Fig. 2). (One of the springs is mounted at each joint). From a plaster of Paris mould of the patient's wrist area (just proximal to the styloids) a 2-inch (50 mm) wrist cuff (Fig. 2) is made using a tough thermoplastic material approximately $\frac{1}{8}$-inch $(3 \mathrm{~mm})$ thick (Formasplint or equivalent will suffice). It is necessary to cover the plaster mould with the same thickness felt liner as it is going to be used to pad the finished cuff, before moulding the cuff. This ensures a snug form fit with a good distribution of the load that the twisting action of the splint puts on the wrist area. As can be appreciated this is important to avoid pressure sores or abrasions due to a loose or sloppy fitting cuff. The wrist cuff is then attached to the forearm cuff by means of two $\frac{3}{16}$-inch $(5 \mathrm{~mm})$ stainless steel connecting rods which are cut to the individual's length (Fig. 2). The four attachment points each consist of a 'ball-joint' (Fig. 2) which give a 'universal type action, in order to allow for the free twisting action which is required during pronation/ supination (Figs 2 and 3 ).

Till recently a RM2 Rose-bearing, otherwise known as a 'Rod-end connector' was used as a joint. However after considerable use, a few of these joints developed a common problem which impeded their free movement. This occurred when the joints were put through a full range of movement and the inner brass cup splitbush made contact with the $8 \mathrm{BA}$ retaining nut on the locating stud of the joint, causing, after repetitive action, the fine edge of the brass liner to be 'bruised' down onto the ball of the joint and restricting its free movement with a resulting stiffness to the pronation/supination action of the splint. In order to overcome this problem a nylon ball joint was designed and manufactured, which provides a more than adequate enough range of movement to the splint. The spring power for pronating the splint is supplied by two specially made up springs (Fig. 2) using 'piano spring wire' or equivalent 'spring hard stainless steel wire' using a gauge wire which is suited to the patient's requirements. Normally a range of wire from $15 \mathrm{G}$ to ${ }_{7} \mathrm{G}$ is required. These two springs are mounted bilaterally and proximally behind the ball joints on the forearm cuff with the one 'arm' being hooked into position $\mathrm{I} \frac{1}{2}$ inches $(37.5 \mathrm{~mm})$ proximally along the arm joint and the other arm of the spring being 'sprung' into position approximately 3 inches $(75 \mathrm{~mm})$ distally along the connector rod. One inch $(25 \mathrm{~mm})$ Velcro straps are used to retain the splint in position on the patient's arm. The four cuffs being padded with $\frac{1}{4}$-inch $(6 \mathrm{~mm})$ thick Orthopaedic felt which is 'contact glued' into the cuffs. The felt 'breathes' and is 'kind' to the skin and is easily replaceable which is an advantage when applying the splint to the Tetraplegic who has the problem of sweating profusely. By means of a quick release attachment the motorised hand splint is easily fitted to the orthosis.

The quick release attachment consists of two locating studs and a thumb screw which fit onto an adaptor plate on the wrist cuff of the orthosis.

\section{Case Report}

J. P.-A I9-year-old university student was admitted to the Spinal Unit at Conradie Hospital in March I97I after having been injured at his initiation ceremony. He had sustained a crush fracture of the fifth cervical vertabra with a complete $\mathrm{C}_{5}$ neurological lesion. Crutchfield tongs were inserted and he was treated on a pack bed for 12 weeks. After rehabilitation over a period of Io months he was discharged from hospital.

The following year, although still a $\mathrm{C}_{5}$ complete neurological lesion, he returned to 

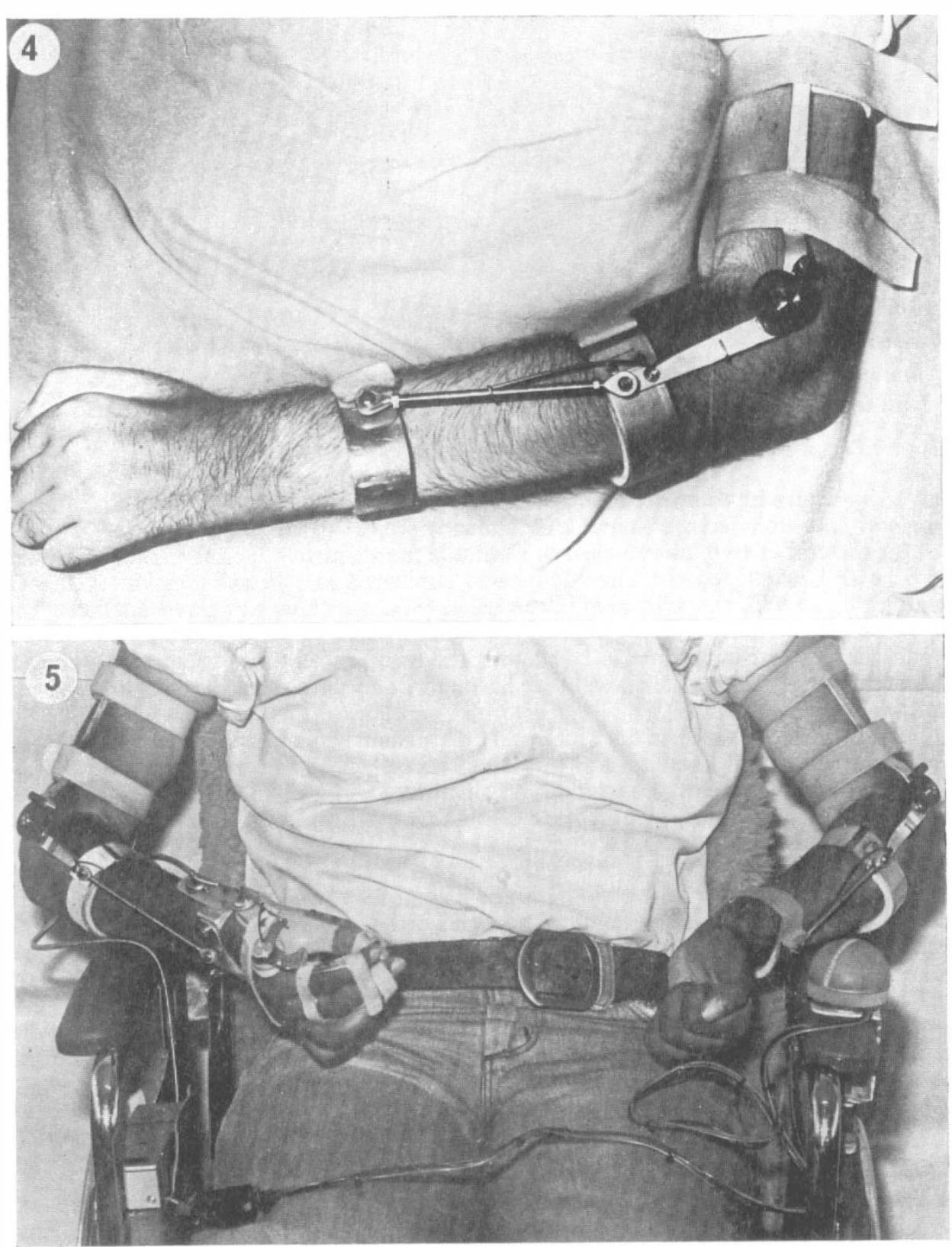

FIG. 4

Orthosis applied to arm.

FIG. 5

Bilateral orthosis applied with a motorised hand splint on right. Forearms in pronation. 


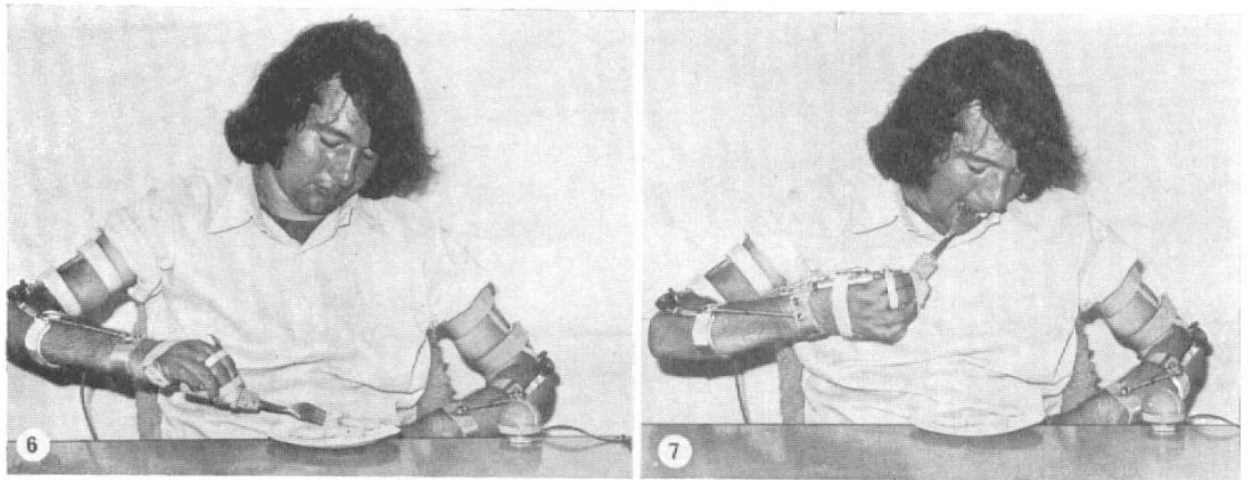

FIGs 6 and 7

Patient feeding himself by means of the orthosis fitted with a $\mathrm{R}$ motorised hand splint. The switch control of motor is on the left of the patient.

university where he completed his Bachelor of Arts Degree in 1975, four years after his accident. He attended the Spinal Unit annually for urological follow-up.

At the end of 1975 he returned to Conradie for a course of splint training. By this time he had developed the often inevitable supinated and flexed position of the $\mathrm{C}_{5}$ tetraplegic arm with the wrist held in extension (Fig. I). This hampered the fitting of a motorised Engen hand splint. Both physiotherapy and occupational therapy assisted in overcoming these contractures. To prevent the recurrence of these contractures and to enable the patient to more effectively use his motorised splint, the orthosis was developed, and applied (Figs 4 and 5).

As a result, for the first time in 4 years the patient was able to feed himself (Figs 6 and 7). Typing and hand control of his motorised wheelchair were also made easier. His degree of independence was significantly increased with the ability to use his motorised hand splint. The patient, who in spite of obtaining a degree had lost motivation, now regained it and is continuing his studies.

During the early stages it was noticed that the tension in the spring providing for the triceps action had to be decreased, as the patient developed too powerful an opposing biceps action, which hindered him when the orthosis was removed. However this setting is easily adjustable at the joint, as already described. The technician also stressed the point that the front cuff should be well applied to prevent any free movement of the cuff over the forearm (Fig. 5).

The patient is still wearing this orthosis daily, 2 years after fitting. He states that he is dependent on it and that an added advantage is that it can be worn under his clothes.

To date four patients have been fitted with this orthosis (three bilateral and one unilateral). Obviously the motivation and intelligence of the patient are important factors in selecting patients to be fitted.

Acknowledgement. We wish to thank Dr D. F. Smith, Medical Superintendent, for permission to publish and the Occupational Therapy and Physiotherapy Departments of Conradie Hospital whose rehabilitative programmes were essential for the success of the project.

\section{RÉSUMÉ}

Une élisse qui donne une extension active et une pronation de l'avant-bras pour le malade paraplégique de $\mathrm{C}_{5}$ complet est introduit. L'éclisse triomphe de, et empêche l'événement du bras plié et supine du tétraplégique $\mathrm{C}_{5}$. Des détails techniques et un reportage du cas sont inclus. 


\section{ZUSAMMENFASSUNG}

Eine Orthese für aktive Extension des Ellbogens und Pronation des Unterarmes bei C5 Tetraplegikern wird beschrieben.

Die Orthese korrigiert und verhindert die Flexions- und Supinationsstellung des Armes bei $\mathrm{C}_{5}$ Tetraplegikern.

Technische Information und Bericht eines Behandlungsfalles sind im Vortrag mit eingeschlossen. 